Arhe XVI, 32/2019

UDK 1

DOI https://doi.org/10.19090/arhe.2019.32.57-79

Originalni naučni rad

Original Scientific Article

\author{
GORAN RUJEVIĆ ${ }^{1}$ \\ Univerzitet u Novom Sadu, Filozofski fakultet
}

\title{
ISPRAZNOST NEPRIRODNOSTI
}

\begin{abstract}
Sažetak: Argument neprirodnosti se koristi za opravdavanje pripisivanja (najčešće) negativne vrednosti stvarima ili postupcima time što se oni opisuju kao neprirodni. Predmeti primene ovog argumenta su raznoliki, počev od tvrđenja o neprirodnosti genetički modifikovanih organizama, pa do neprirodnosti homoseksualnih odnosa. Značenje neprirodnosti se u tim slučajevima konkretizuje ili kao artificijelnost ili kao disharmoničnost ili kao kršenje prirodne svrhe. Razmatranjem svake od ovih instanci, dolazimo do zaključka da pojam neprirodnosti ni u jednoj od njih nema suvislu i doslednu upotrebu. Artificijelnost nije neprirodna, jer i ono što je veštačko prati tokove i zakone prirode. Disharmoničnost je loš opozit prirodi jer je postuliranje harmoničnosti prirode neosnovana pretpostavka. Kršenje prirodne svrhe je pogotovo problematičan vid argumenta neprirodnosti jer se $\mathrm{u}$ njemu tendenciozne namere maskiraju u ruho objektivnosti. Jedini smisleni opozit pojmu prirodnog jeste pojam natprirodnog, a njemu nema mesta u prosuđivanju realnih stvari i događaja.
\end{abstract}

Ključne reči: harmonija, homoseksualnost, neprirodno, prirodno, svrha, veštačko

\section{UVOD}

Neka je izučavanje moralnih principa i načelnih zakonitosti primarna delatnost jednog etičara, i dalje razmatranje pojedinačnog delanja takvoj osobi nije stran poduhvat, utoliko pre ukoliko se kroz pojedinačno delanje namerava dosegnuti ono opšte koje može da posluži kao ključ za druge slučajeve. Argumentacija moralnog vrednovanja po definiciji potpada pod sferu racionalnosti jer se sastoji od pružanja razloga za bilo kakav moralni sud, te time obezbeđuje postojanje predmeta za moralnu refleksiju. Dabome, ništa ne garantuje da će domet

\footnotetext{
${ }^{1}$ E-mail adresa autora: goran.rujevic@ff.uns.ac.rs
} 
te refleksije u svakom konkretnom slučaju biti iscrpan i zadovoljavajući, jer kao što su ljudi u stanju da donesu istančana moralna prosuđivanja, jednako često, ako ne i češće, možemo zateći moralne sudove koji nisu ništa složeniji od prostih sudova dopadanja. S obzirom na to, pogrešno bi bilo diskvalifikovati svaku argumentaciju moralnog vrednovanja kao parcijalni sud ukusa, a još pogrešnije bi bilo delegirati čitavu tu problematiku na pitanje legaliteta $i$ jurističkog procenjivanja primenljivosti opšteg zakonskog propisa na konkretan događaj. Uostalom, nije neviđeno da moralna argumentacija vremenom bude kodifikovana i preraste u obrazloženje zakonske norme.

Jedan takav slučaj argumentacije nameravamo da ispitamo na predstojećim stranicama. Reč je o argumentu koji svoje lice pomalja u brojnim i raznolikim instancama, ali svima njima pokušava da pruži utemeljenje koje je pogotovo relevantno u savremenom društvu naučnotehničkog karaktera. Reč je o svojevrsnom naturalističkom argumentu kojeg podrobnije želimo da ispitamo u njegovoj negativnoj varijanti (razmatranje pozitivnog naturalističkog moralnog principa je neuporedivo složeniji zadatak). Pod negativnom varijantom naturalističkog moralnog argumenta smatramo takvo obrazloženje negativnog moralnog vrednovanja nekog postupka koje se na bilo kakav način svodi na to da je taj postupak neprirodan ili protivan prirodi. Relevantnost ovog argumenta u savremenom društvu izgleda očevidna - kako bolje upoznajemo mehanizme kroz koje se odvija prirodni svet, tako je smisleno očekivati da ćemo bolje znati šta se tim mehanizmima protivi, a karakterisanje nečega kao neprirodnog imalo bi veću težinu.

Kao što je već pomenuto, argument neprirodnosti aktualno se primenjuje na mnoge oblike ljudskog ophođenja, i to, zanimljivo, sa vrlo raznolikih ideoloških pozicija. Neprobitačna upotreba genetički modifikovanih organizama potkrepljuje se tvrdnjom da su takvi organizmi neprirodni. Upotreba atomske energije kritikuje se sa stanovišta da su uticaji koje ekstrakcija takve vrste energije ima na okoliš neprirodni. Homoseksualni odnosi se nazivaju neprirodnim, što se potom koristi kao obrazloženje za nepriznavanje istopolnih brakova, negiranje mogućnosti usvajanja dece za istopolne parove, a gdegod i za kriminalizaciju samih istopolnih odnosa. Izvesno je da se kvalifikacija 
neprirodnog ovde uzima $\mathrm{u}$ različitim značenjima i sa različitim intencijama, što samo potcrtava potrebu za analizom tog argumenta, jer disputovanje jedne upotrebe ne mora lako da se prenosi na drugu.

Usled važnosti i dalekosežnosti same problematike, ovom prilikom ćemo se najviše usredsrediti na upotrebu argumenta neprirodnosti za vrednovanje istopolnih odnosa, a oni aspekti u kojima postoje značajne sličnosti i razlike sa drugim upotrebama tog argumenta biće posebno istaknuti. S obzirom na to, dužni smo da čitaocima već sada napomenemo sentiment sa kojim autor ovog teksta pristupa njegovom pisanju. Argument neprirodnosti istopolnih odnosa dugo je, čak vekovima, korišćen za demonizaciju jedne grupe ljudi i upotrebljavan je kao opravdanje za gnusna, nehumana i, u najboljim slučajevima, bezobzirna nedela protiv njih. Brojni nevini životi su zagorčani, unesrećeni i ugašeni pod pokriljem ovog argumenta, i uz sve korake napred koji su do danas ostvareni, prosto je sramotno da ovo obrazloženje i dalje opstaje u raspravi o ljudskim pravima. Autoru ovog teksta će tako biti veliko zadovoljstvo da razobliči taj argument $\mathrm{i}$ da ga pokaže u njegovoj ništavnosti. Ne smatramo da je ovim ugrožena valjanost analize koja će imati taj rezultat, ta analiza već je domišljena u trenutku pisanja ovog teksta i sricanje ovih reči služi samo prezentovanju iste post festum. Štaviše, priznavanje ovog sentimenta služi jačem utemeljenju konačnog zaključka, jer, da je taj sentiment jedino što potkrepljuje zaključak, čitava analiza na narednim stranicama bi bila samo gubljenje vremena. Drugim rečima, ovim priznanjem nameravamo da iz ruku izbijemo prigovor o pristrasnosti i da podsetimo da silinu dokaza ne nosi motivacija, već demonstracija. A da bi se ta demonstracija uspešno sprovela, prilikom analize argumenta neprirodnosti bićemo primorani da artikulišemo taj argument u brojnim instancama sa kojima se ne slažemo. Usled toga, molimo čitaoce ovog teksta za strpljenje i insistiramo da ga ne čitaju u odlomcima, već isključivo u celini.

Uz ova ograničenja, red je da postuliramo hipotezu koja čini kičmu ove analize: argument neprihvatljivosti delanja na osnovu neprirodnosti je ništavan usled toga što je pojam neprirodnog besmislen. Antecedensnu tvrdnju ove hipoteze vredi precizirati: pojam neprirodnog je besmislen utoliko što ne stoji u doslednom odnosu sa drugim 
pojmovima na osnovu kojih formira svoju konotaciju. Iz ovoga možemo, kao korolar, naslutiti da se pojam neprirodnog koristi kao erzac za neki drugi pojam čija se slabija argumentativna vrednost time želi prikriti.

Da bismo bili u stanju da ispitamo navedene tvrdnje, neophodno je da isprva preciznije naznačimo što je moguće više značenja u kojima se termin neprirodno upotrebljava. Jasno je da smo u ovom pogledu direktno upućeni na višestrukost značenja pojma prirode. Srećom, u ovoj analizi ne moramo ispitivati svaki opozit sve i jednog pojma prirode, radije, pokušaćemo da ih klasifikujemo u nekoliko grupa, trudeći se da pri tom budemo što iscrpniji. Pre svega, o prirodi se može govoriti ili načelno, u smislu zbira stvari koje sačinjavaju prirodu, ili pojedinačno, u smislu inherentnih karakteristika stvari. Načelno razumevanje prirode može biti ili totalno, gde priroda postaje sinonim za sve, ili s obzirom na neku odabranu osobinu, tako da priroda može biti sve ono što postoji objektivno, sve ono što postoji i što je materijalno, sve ono što postoji i što je nastalo spontano. Kako se uspostavljaju suprotnosti spram svakog od ovih razumevanja?

Za totalno načelno razumevanje prirode, suprotnost bi moralo biti nešto što ne postoji, to jest, ako priroda obuhvata sve, za neprirodno nije ostalo ništa - izvesno je da ovo nije dosledno razumevanje pojma neprirodno, jer nazivati bilo koju stvar neprirodnom u tom značenju bi bilo kontradiktorno. Nešto drugačiju situaciju zatičemo na polju specifičnih načelnih razumevanja prirode. Naime, ovde je jasno da se argument neprirodnosti ne upotrebljava spram svake od navedenih istaknutih osobina. Kada se nešto naziva neprirodnim, time se (najčešće) ne misli da je to nešto subjektivno (kao opozit objektivnoj prirodi), niti nešto nematerijalno (kao opozit materijalnoj prirodi), već pre nešto što je veštačko, artificijelno, što nije nastalo spontano, te će to biti ta istaknuta osobina na koju ćemo se mi fokusirati tokom ove analize.

Najzad, što se tiče pojedinačnog razumevanja prirode (kao prirode neke stvari), isprva se čini da argument neprirodnosti tu ne može da pronađe adekvatno uporište. Opoziti pojedinačnih priroda bi i sami morali biti pojedinačni, te bi ih postojalo onoliko koliko ima stvari kojima možemo pripisati neku prirodu ili, makar, onoliko koliko ima vrsta kojima pripisujemo neku esencijalnu karakteristiku, ukoliko smo 
naklonjeni da na taj način razumevamo svet. Kakvo god da je naše nagnuće u pogledu ovog mlađeg brata problema univerzalija, reklo bi se da argument neprirodnosti ne smera na osporavanje inherentnih karakteristika. Ipak, to ne znači da se argument neprirodnosti ne može artikulisati kroz suprotnost sa pojedinačnim razumevanjem prirode stvar je $u$ tome što se neprirodnost nečega u tom kontekstu ne izražava $u$ smislu nepodudarnosti nečega sa sobom, već u nepodudarnosti nečega sa već postojećom mrežom entiteta koji stoje u unapred determinisanim odnosima, rečju, u nepodudarnosti sa prirodnim poretkom. Način na koji se pojam poretka ovde razumeva jednako ima uticaja na to kakav opozit se formira $\mathrm{u}$ argumentu neprirodnosti. Poredak se može shvatati kao faktički ili kao projektovani. Faktički poredak bi bio prosti status quo, a projektovani poredak se najbolje može razumeti kao ideal ili cilj ka kojem se svi procesi kreću, takoreći nekakva implicirana svrhovitost.

S obzirom na sve rečeno, možemo da prepoznamo nekoliko distinktnih vrsta neprirodnosti na koju argument neprirodnosti može da smera. To može biti a) neprirodno kao nešto što se ne javlja spontano (ono veštačko); b) neprirodno kao ono što se protivi sadašnjem harmoničnom poretku (ono disharmonično); c) neprirodno kao ono što ne ispunjava svrhovitost prirode. Svakoj od ovih varijanti možemo pridodati neki od konkretnih argumenata neprirodnosti - uzmimo, kao primer, argumente o neprirodnosti homoseksualnih odnosa. Gledano kroz ove prizme, oni zadobijaju oblike: a) homoseksualni odnosi su neprirodni jer se ne javljaju u prirodi, već su izmišljotina ljudske dekadencije; b) homoseksualni odnosi su neprirodni jer narušavaju postojeću harmoniju uparivanja muškog i ženskog; c) homoseksualni odnosi su neprirodni jer ne mogu da ostvare svrhu sa kojom se odnosi uopšte javljaju, a to je stvaranje dece. Neki od ovih argumenata se vrlo lako daju materijalno pobiti, pogotovo argument o tome da $\mathrm{u}$ divljoj prirodi nema instanci homoseksualnosti. Nas, međutim, ovde ne interesuje pobijanje ovih argumenata kroz pronalaženje kontraargumenata, nas interesuje da pokažemo da je svaki od ovih argumenata besmislen samim tim što se poziva na pojam neprirodnog. Pogotovo će nam biti zadovoljstvo da dekonstruišemo poslednji tip argumenta neprirodnosti, koji je od svih pomentih najproblematičniji utoliko što najefikasnije maskira nevaljane 
pretpostavke. Stoga, glavni nam je zadatak da svaki od ovih argumenata, tačnije, razumevanja neprirodnog, podvrgnemo analizi.

\section{PRIPREMA TERENA}

Srećom, u taj zadatak ne moramo da se upustimo sami, i pre pohoda vredi se raspitati da li u njemu možemo pronaći pouzdane saveznike. U više navrata se u istoriji filozofije može zateći tematizacija odnosa između ideje prirode i ljudskog delanja. Tako među antičkim sofistima pronalazimo prva razmatranja o odnosu između koncepata physis, koji označava prirodu i prirodni poredak, i nomos, kojim se obuhvataju ljudski uzusi delanja, pravila i zakoni. Ono u čemu se većina sofista slagalo jeste da physis predstavlja nepromenljive i neodoljive zakonitosti, univerzalne, nužne i neumitne, dok su obrasci koji se vezuju uz nomos partikularni, lokalni, promenljivi, konačno i propadljivi. U ovim refleksijama prvi put zatičemo prepoznavanje ključne distinkcije kršenja zakona iz ove dve oblasti - kršenje zakona koji sačinjavaju nomos je nešto što, u odgovarajućim okolnostima, za sobom povlači kaznu, kršenje zakona koji sačinjavaju physis nije moguće.

Nesuglasice među sofistima postoje na polju toga koji od ova dva koncepta nosi primat. Neki, kao što su Hipija i Kalikle, smatraju da se veća pravednost nalazi u životu koji je usklađen sa prirodom, dok sa druge strane imamo sofiste kao što je Kritija, kod kojeg zatičemo ideju da u prirodi vlada haos koji se ima nadomestiti ljudskim zakonima. ${ }^{2}$ Neka od ovih učenja kasnije se mogu prepoznati kod stoika i epikurejaca.

Znatno kasnije, o sličnoj temi govori Monteskje [Charles Louis de Secondat] na samom početku dela $O$ duhu zakona [De l'esprit des lois]. Prva knjiga ovog spisa započinje razmatranjem ideje zakona uopšte, kojom prilikom oni bivaju određeni kao „nužni odnosi koji proizilaze iz prirode stvari," ${ }^{3}$ te time obuhvataju kako zakone prirode, tako i zakone čiji je autor čovek. Vredi napomenuti da Monteskje smatra da su i zakoni

\footnotetext{
${ }^{2}$ Nihal Petek Boyaci Gülenç, „An Enquiry on Physis-Nomos Debate: Sophists” u: Synthesis Philosophica 61(1/2016), str. 39-53.

${ }^{3}$ Monteskje, $O$ duhu zakona, Gradac, Čačak, 2001, str. 17.
} 
prve i zakoni druge vrste stvoreni, ovi prvi od strane Stvoritelja, a ovi drugi od strane samih ljudi, što ih postavlja u vrlo jasan odnos precedencije, usled čega ,odnosi jednakopravnosti postoje i pre pozitivnog zakona koji ih ustanovljuje [...] Međutim, daleko od toga da svet razumnih bića podleže onako skladnom upravljanju kao fizički. Jer, iako i onaj prvi ima zakone koji su po svojoj prirodi nepromenljivi, ne sledi ih postojano kao što fizički svet sledi svoje zakone. Razlog je u tome što su pojedinačna razumna bića ograničena po svojoj prirodi i otuda podložna zabludi; s druge, pak, strane, u njihovoj je prirodi da delaju sama od sebe. Ona, dakle, ne slede postojano svoje prvobitne zakone; štaviše, ne slede uvek čak ni one koje sama donose."4

Bitno je zapaziti da isticanje postojanosti prirodnih zakona $\mathrm{u}$ ovom navodu nije svodivo na nekakav naturalistički stav u kom se zakoni društva izvode iz zakona prirode. Štaviše, za Monteskjea su relevantni prirodni zakoni nešto drugačiji od onoga što bismo mi pod time podrazumevali, za njega je prvi prirodni zakon onaj koji nam daje svest o stvoritelju i „nosi k njemu." ${ }^{5}$ Iako Monteskje ne govori o strogoj dedukciji čovekovih zakona iz prirodnih, kao jasan motiv njegove teorije ostaje ideja da se ovi prvi ipak usaglašavaju sa ovim drugima, makar u vidu toga što ih uzimaju u svom temelju. Tako imamo ideju da različiti zakoni pripadaju različitim oblicima vladavine shodno njihovoj prirodi, ili, još bazičnije, da fizičke karakteristike zemlje imaju nedvosmislenog udela u tome kako će se na njoj živeti. ${ }^{6}$ Konverzno, opravdano je naslutiti da bilo kakvo delanje koje bi bilo zvano neprirodnim ne bi moglo naći svoje mesto u pozitivnim zakonima, a lako bi se moglo sa njima i kositi.

Autor čiji će uvidi nama ovom prilikom biti od najvećeg interesovanja jeste devetnaestovekovni britanski filozof Džon Stjuart Mil [John Stewart Mill], i to prvenstveno u jednom odlomku njegovih eseja o religiji koji je na našem jezičkom području preveden pod naslovom Prirodno i neprirodno. Ovaj odlomak se najneposrednije dodiruje na temu koju smo mi ovde otvorili, i u izvesnim aspektima daje sasvim

\footnotetext{
${ }^{4}$ Isto, str. 18.

${ }^{5}$ Isto, str. 19.

${ }^{6}$ Isto, str. 22.
} 
konkluzivne odgovore na neke od nabrojanih oblika argumenta neprirodnosti. Nema boljeg mesta na kom se to podudaranje može jasno prepoznati do Milovih reči o cilju sa kojim piše esej: „Namera je da se istraži istinitost učenja koje je proglasilo prirodu kao merilo za ispravno i pogrešno, za dobro i loše, ili koje na neki način ili u nekom stepenu smatra pohvalnim ili odobrava da se priroda sledi, da se podražava ili da joj se iskaže pokornost." ${ }^{\text {7 }} \mathrm{S}$ obzirom na to, ovaj naš opit se možda još bolje može razumeti kao nastavak diskusije čije temelje je jasno postavio sam Mil, jer ćemo se potruditi da obuhvatimo i one aspekte koje je Mil iz specifičnih razloga izostavio iz svoje analize.

Uvod u Milovu raspravu započinje pristupom koji smo pokušali emulirati na početku ovog teksta, a to je uz konstataciju da je termin prirodno poprimio raznorazna značenja. U svom tekstu, on će efektivno identifikovati tri značenja pojma prirode - koje provizorno nazivamo faktičko, kolokvijalno i svrhovito, iako će on u svojoj analizi pažnju usmeriti samo na prva dva. Do zadovoljavajuće definicije faktičkog pojma prirode Mil dolazi postupno. Prvo započinje od ideje individualne prirode, koju određuje kao „skup sposobnosti i svojstava [nekog objekta]: načina na koje oni deluju na druge stvari (ubrajajući među njih i čula posmatrača) i načina na koje druge stvari deluju na njih." ${ }^{8}$ Ubrzo zatim, Mil nas podseća da u to moramo ubrajati i karakteristiku svesnosti koju poseduju čulna bića, što jasno ukazuje na njegovu intenciju da liniju rezonovanja koju ovde započinje konačno dovede do pitanja intencionalnog izbora delanja. Ovo određenje prirode sasvim je blisko onom koje smo mi prethodno nazvali pojedinačnim razumevanjem prirode.

U sledećem koraku definisanja, Mil sublimira ovo predmetnoorijentisano određenje $u$ određenje koje je orijentisano na posmatrača (da ne kažemo teoretičara), te prirodu neke stvari definiše kao „njenu ukupnu sposobnost da ispolji fenomene." $\mathrm{U}$ tome Mil prepoznaje da se ispoljavanje fenomena, iako raznoliko, konačno odvija po nekim

\footnotetext{
${ }^{7}$ Džon Stjuart Mil, Prirodno i neprirodno, Karpos, Loznica, 2008, str. 29-30.

${ }^{8}$ Isto, str. 20.

${ }^{9}$ Isto, str. 21.
} 
pravilnostima koje se mogu pratiti. Ukoliko sada ono pojedinačno razumevanje poopštimo, apstrahujemo, doći ćemo do ideje da je priroda skup sposobnosti svih stvari, i ako na to dodamo mogućnost uočavanja pravilnosti iliti zakonitosti, dolazimo do sledeće definicije: „Priroda označava zbor svih fenomena, zajedno sa uzrocima koji ih stvaraju: ona uključuje ne samo ono što se dešava, nego i sve ono što može da se desi. ${ }^{10}$ Ova odredba sasvim dobro odgovara shvatanju prirode koje smo mi prethodno nazvali načelnim.

Poslednja i najpreciznija iteracija Milovog faktičkog pojma prirode glasi: „Priroda je, dakle, u svom najjednostavnijem značenju, kolektivno ime za sve stvari, aktualne ili moguće, ili (da kažemo što tačnije) naziv za način na koji se stvari dešavaju, koji nam je delimično poznat a delimično nije."11 Vredi zapaziti da se u ovoj preciziranoj definiciji može zateći inkorporirana ideja prirodnog poretka. Ovakvom shvatanju prirodnosti Mil posvećuje najveći deo svog eseja, no nama će elementi te analize biti korisni nešto kasnije, tako da za sada ostavljamo faktički pojam prirode po strani i prelazimo na preostala dva.

Nasuprot ovog faktičkog pojma prirode, Mil prepoznaje drugi, kolokvijalni pojam koji se javlja u ,uobičajenom obliku govora prema kojem je priroda suprotna umetnosti, a prirodno veštačkom."12 U ovom elementu se postupci naše i Milove analize unekoliko razilaze, jer mi smo ovakvo razumevanje već grupisali pod načelno shvatanje prirode, uz napomenu da ovde govorimo o specifičnosti razumevanja ideje neprirodnog. Ovo razilaženje u koracima, međutim, ne donosi nikakve otežavajuće okolnosti u pogledu upotrebljivosti Milove analize za naše pitanje, što će se pokazati ubrzo, jer upravo Milova kritika ovog razumevanja prirode stoji $u$ temelju naše kritike prvog tipa argumenta neprirodnosti.

Treći i poslednji pojam prirode koji Mil pominje je pojam koji nastaje iz konkretne upotrebe termina priroda u kontekstu vrednovanja ljudskog ponašanja: „Čini se, međutim, da upotreba reči 'priroda' kao

\footnotetext{
${ }^{10}$ Isto.

${ }^{11}$ Isto, str. 22.

${ }^{12}$ Isto, str. 23.
} 
etičkog pojma otkriva i treće značenje u kojem priroda ne označava ono što jeste, nego ono što treba da bude ili pak pravilo ili normu onoga što treba da bude." ${ }^{\prime 13}$ Međutim, na veoma očiglednom hjumovskom tragu da iz jeste ne može da sledi treba, Mil je krajnje dismisivan u pogledu ovog pojma, smatrajući ga konačno neispravnim, nemerodavnim, te ga izostavlja iz dalje diskusije i usredsređuje se na dva prethodna značenja. Nevaljanost premisa ipak nije uvek sprečavala ljude da ih upotrebljavaju u svojoj argumentaciji i na temelju ovog shvatanja koje Mil odbacuje, a koje smo mi provizorno nazvali svrhovitim, konstruisana je čitava familija pervertiranih doktrinarnih galimatijasa koji vulgarno interpretiraju uvide savremene nauke, pogotovo evoluciona biološka otkrića, kao opravdanja za razne oblike ukidanja slobode. Najočigledniji predstavnik ove familije je učenje socijalnog darvinizma, ali i druga, možda pritajenija, no ništa manje štetna stanovišta, baš kao što je treći tip argumenta neprirodnosti.

Naš sledeći korak će se sastojati u tome da konačno razmotrimo svaki od tri tipa argumenta neprirodnosti, uvidimo da li se na neke od njih može odgovoriti već iz registra Milovog eseja (a obećali smo da može), te da pokušamo da proširimo opseg tog rezonovanja i na ona područja koja su ostala isključena iz Milove analize.

\section{PRIRODA I SPONTANOST}

Prvi tip argumenta neprirodnosti izjednačava taj termin sa onim veštačkim. Prirodno je ono što se spontano javlja u okolišu, u divljoj prirodi, bez intervencije čoveka, dok se ono neprirodno javlja kao kvarenje i propadanje usled ljudskog uplitanja. Ono spontano je u ovom kontekstu pretpostavljeno kao nešto inherentno dobro i poželjno, a ono veštačko je loše i štetno. Konkretizovano na slučaj homoseksualnih odnosa, ovaj argument ih obeležava kao nepoželjne i ističe ih kao anomalije koje su specifične samo ljudskoj perverziji. U materijalnom pogledu, neispravnost ovog argumenta je konkluzivno dokazana već decenijama. Homoseksualno ponašanje javlja se u mnogim slučajevima,

\footnotetext{
${ }^{13}$ Isto, str. 29.
} 
u raznoraznim stepenima zastupljenosti i bez ikakve korelacije sa fiziološkim poremećajima. ${ }^{14}$

Slabost ovog argumenta pronalazi se $u$ njegovim samim vrednosnim pretpostavkama. Ne postoji nikakva obaveza da se spontane stvari izjednače sa dobrim, a veštačke sa lošim. Ako se tvrdi da su sve veštačke stvari loše, onda taj sud mora da se primeni na sve artificijelne stvari, počev od ljudskih institucija (što, priznaćemo, nije nečuveno stanovište), ali i nekih nesumnjivo pozitivnih proizvoda, kao što su lekovi, alati i slično. Ali, možda se ovde želi povući implikacija u obrnutom smeru, odnosno, da se tvrdi da, ako je nešto loše, onda je to bez izuzetka veštačko. I ovde možemo pronaći vrlo jednostavne kontraprimere, kao što su zemljotresi sasvim prirodne pojave, ali ih retko možemo opisati kao dobre. ${ }^{15}$

No, još temeljniji problem se može pronaći u prvoj postavci ovog argumenta, a to je ideja da se ono neprirodno shvati kao ono veštačko. Mil je vrlo koncizan prilikom kritikovanja upravo ovog stava: , [U]metnost je isto tako priroda kao i bilo šta drugo, a sve veštačko je istovremeno $\mathrm{i}$ prirodno. Naime, umetnost ne poseduje sopstvene nezavisne sile: ona nije ništa drugo do korišćenje prirodnih sila u određene svrhe. Pojave koje su nastale ljudskim delovanjem, ništa manje nego one koje su, što se nas tiče, spontane, zavise od svojstava elementarnih sila ili od elementarnih supstancija i njihovih jedinjenja."16 Doista, svaka veštačka tvorevina, ma koliko da odudara od prirodnog krajolika ili od hipotetičkog divljeg stanja, i dalje je sasvim prirodna posledica upotrebe prirodnih sposobnosti kojima je čovek obdaren.

${ }^{14}$ Paul L. Vasey, „Homosexual Behaviour in Primates: A Review of Evidence and Theory" u: International Journal of Primatology, Vol. 16, Iss. 2.(1995), str. 173-204. Autor ovog članka upravo ističe da istraživanja o homoseksualnom ponašanju životinja imaju velikog značaja za ljude, jer se postavljaju kao merilo za prirodnost ili abnormalnost ponašanja (str. 174).

${ }^{15}$ Upravo su zemljotresi i njihova vrednosna interpretacija predmet Kantovog teksta o istoriji zemljotresa. Videti Immanuel Kant, „Geschichte und Naturbeschreibung der merkwürdigsten Vorfälle des Erdbebens" u: Immanuel Kant's kleinere Schriften zur Naturphilosophie. Zweite Abtheilung (Hg. J. H. Kirchmann), L. Heimann's Verlag, Berlin, 1783, str. 333-372.

${ }^{16}$ Džon Stjuart Mil, Prirodno i neprirodno, str. 23. 
Proizvodi ljudske veštine specifični su samo utoliko što su ljudski, jednako kao što svaki biom na ovoj planeti nosi obeležja koja su rezultat prisustva specifičnih živih oblika. Velelepni termitnjaci se javljaju samo tamo gde ima termita i predstavljaju uočljiv element pejzaža u kom se zatiču. Hoće li se i za ta „zdanja” reći da su neprirodna?

Sasvim prigodno, Mil se u okviru svog teksta mestimično dotiče i samog problema izjednačavanja dobrog sa spontanim i lošeg sa veštačkim. Tako o veštačkom kaže: „Izmena i usavršavanje prirode je sam cilj i predmet delanja. Ako je prirodan tok stvari savršeno ispravan i zadovoljavajući, svako delovanje uopšte predstavljalo bi neopravdano uplitanje." ${ }^{.17}$ A o mogućnosti da su prirodne stvari redom poželjne se izjašnjava: „Kada se trezveno razmisli, priroda gotovo svakodnevno čini one stvari zbog kojih ljudi, ukoliko ih učine jedni drugima, odlaze na vešala ili u zatvor." 18 Uzeto zajedno, ovo su vrlo jasne indikacije da neprirodno nije smisleno identifikovati sa veštačkim, a čak i ako se to učini, iz toga ne možemo izvlačiti dosledne zaključke o dobru i zlu.

Pored primera koji smo mi odabrali da nas prati u ovoj analizi, ovakav nevaljan argument neprirodnosti se upotrebljava i u drugim kontekstima. Genetički modifikovani organizmi se obeležavaju kao loši jer su neprirodni, nastali ljudskom intervencijom nad naslednim materijalom, a ne spontanim procesima u divljini; aditivi za konzerviranje, bojenje i menjanje ukusa hrane su štetni jer nisu inherentni toj hrani, već su joj veštački dodati. A opet, genetički inženjering se oslanja na poznavanje proučenih prirodnih biohemijskih procesa koje usmeravamo po želji, a hemijski aditivi se koriste upravo zbog toga što prirodno imaju željeno hemijsko dejstvo na hranu kojoj se dodaju. Ovim, dakako, ne želimo reći da je svaki aditiv poželjan, jer nije, ali nepoželjnost ne proizilazi iz neprirodnosti, već iz neželjenih (na primer kanceroganih) efekata za koje je utvrđeno da ih neki aditivi imaju. Isto važi i za genetički modifikovane organizme, njihov najveći rizik je ukoliko su nedovoljno dobro ispitani i ukoliko se ne poznaju posledice dejstava takvih organizama kako na čoveka, tako i na ekosisteme uopšte.

\footnotetext{
${ }^{17}$ Isto, str. 36.

${ }^{18}$ Isto, str. 46.
} 
Ali, to je problem koji nije posledica veštačkosti, jer, tehnički gledano, i genetički modifikovani organizmi i hemijski aditivi jesu sasvim jasno deo prirode i funkcionišu shodno svojoj prirodi; pre je u pitanju problem koji je posledica nedovoljnog znanja i kratkovidosti, za šta se lakše možemo složiti da za sobom povlači negativnu vrednosnu procenu. Kada postoji adekvatniji argument, upotreba nevaljanog argumenta je utoliko štetnija.

\section{PRIRODA I HARMONIJA}

Pređimo na drugi tip argumenta neprirodnosti, onaj koji se zasniva na poziciji da se priroda, ili pre prirodni poredak, prepoznaje kao savršeno harmoničan sistem, te da je ono što je izvan tog sistema, što je neprirodno, štetno zato što narušava status quo koji je već najbolji. Ovaj argument je, u izvesnom smislu, samo izmenjena verzija prethodnog, jer sada više ne govorimo o prirodnosti kao opštoj karakteristici, već o neposrednom odnosu elemenata sistema prirode i samog tog sistema. Vrednosni sud sada nije posledica inherentne karakteristike stvari, već odnosa tih stvari sa drugima. Ali, i pored te sitne razlike, izjednačavanje neprirodnog sa veštačkim je i ovde glavna uporišna tačka argumenta.

Jasno je da se svi prethodni prigovori primenjuju i na ovaj tip argumenta neprirodnosti. Ipak, ovom prilikom ga posebno uzimamo u razmatranje zato što je predstava o harmoničnoj prirodi veoma raširena, kako u današnjici, a još više u prošlosti. Romantičari su poznati po tome da su veličali saglasje prirode, i ta ideja je uspela da se uvuče u razne doktrine, neretko uz pomoć argumenta neprirodnosti kao disharmonije. Ajzaja Berlin [Isaiah Berlin] daje lep pregled ovih ideja u knjizi Političke ideje u doba romantizma [Political Ideas in the Romantic Age]. Naturalističku doktrinu on ukratko opisuje kao ideju da je prirodni poredak uvek snažniji od onih koji ga žele poremetiti, ${ }^{19}$ da je svaki zločin ogrešenje o neku prirodu i neke inherentne svrhe, što dovodi do disharmonije sa svetom $i$, sledstveno, patnje. ${ }^{20}$ Berlin ovakvo učenje

${ }^{19}$ Isaiah Berlin, Political Ideas in the Romantic Age, Princeton University Press, Princeton, 2006, str. 59.

${ }^{20}$ Isto, str. 83. 
opisuje kao objektivnu etiku, kao pokušaj da se principima ponašanja podari isti autoritet kakav imaju zakoni prirode, a u nadi da se izbegnu kaprici promenljivih subjektivnih etika. ${ }^{21}$

Međutim, kao što su se i sofisti ranije sporili oko istog pitanja, ni danas nemamo ništa boljeg razloga da prirodu pojmimo bilo kao harmoničan bilo kao haotičan sistem, tim pre što je krajnje problematično pronaći objektivno merilo uređenosti/haotičnosti. Živi svet izgleda harmoničan u nekom idiličnom krajoliku, ali ako se bliže zagledamo, uviđamo krvave borbe za opstanak. A tvrditi da je taj proces zapravo harmoničan jeste vrlo teško, jer kolabiranje ekosistema i izumiranje čitavih vrsta uopšte nisu retke pojave u čitavoj istoriji naše planete. Reći da stvari ne posmatramo sa dovoljne distance je nepošten argument, jer se tu na svaki kontraprimer može odgovoriti pomeranjem tražene distance, hipotetički dok ne dođemo do one perspektive sa koje su sve specifičnosti savršeno beznačajne. Mil iznosi nešto drugačiji prigovor kada, nakon već pomenutih zapažanja o surovosti prirode, kaže: „Čak i ako pretpostavimo da priroda, priređujući ovakve strahote, suprotno onome kako izgleda, ima dobre ciljeve, niko ne veruje da dobre ciljeve možemo ubrzati ukoliko sledimo taj primer, tj. tok prirode ne treba da bude obrazac koji ćemo oponašati.",22

Ništa bolji nisu pokušaji da se utemeljenje kriterijuma harmoničnosti veže za neku postojeću objektivnu meru, i ti pokušaji gotovo bez izuzetka posežu za entropijom, pogotovo u redakciji koja entropiju tumači kao meru neuređenosti sistema. Ovakvo razumevanje entropije je početničko, zastupljeno u raznim uvodnim ili popularnim lekcijama, ali naposletku je neadekvatno. ${ }^{23}$ Najbolji pokazatelj toga jeste što hipotetičko stanje maksimalne entropije podrazumeva savršeno ravnomernu distribuciju toplotne energije, termodinamičku ravnotežu, što bi teško bilo nazvati stanjem maksimalne haotičnosti. Izgleda da

\footnotetext{
${ }^{21}$ Isto, str. 325.

${ }^{22}$ Džon Stjuart Mil, Prirodno i neprirodno, str. 49.

${ }^{23}$ Detaljnije: Frank L. Lambert, „A Modern View of Entropy” u: Chemistry, Vol. 15, Iss. 1. (2006), str. 13-21.
} 
kategorija harmonije ne predstavlja dobro utemeljenje za bilo kakav naturalistički argument.

Još bolji razlog posebnog sagledavanja ovog argumenta jeste taj da se njegova slična verzija može pronaći u opštim diskusijama o efektu ljudskih radnji na prirodnu sredinu. Za čovekovo ponašanje, privredu, čak i civilizaciju uopšte se kaže da narušavaju prirodni poredak, da nisu u harmoničnom odnosu sa prirodom i da zato štete planeti. Ovde je neophodno da budemo obazrivi, jer uprkos značaju problema klimatskih promena i nedvosmislenim dokazima o tom problemu, u svetskim centrima moći i dalje se vode sporovi oko realnosti globalnog zagrevanja. Činjenice su nesumnjive: klimatske promene postoje i rezultat su ljudske aktivnosti.

Ali, klimatske promene nisu posledica našeg ponašanja koje je grešno zato što je disharmonično sa prirodom, pa sada neka kosmička pravda pokušava da nas prizove pameti pre nego što uništimo planetu. Klimatske promene su prirodna posledica našeg ponašanja; efekat staklene bašte je prirodna posledica povećane količine izvesnih vrsta gasova u atmosferi i prirodno je prisutan na planeti Veneri. Prirodnost klimatskih promena je upravo ono što je kod njih najstrašnije, jer ih čini neumitnim, izvesnim, definitivnim. I nemojmo se zavaravati, koliko god štete da nanosimo planeti, ona je preživela mnogo gore katastrofe i masovna izumiranja; pravi problem je $u$ tome što trenutnim ponašanjem proizvodimo klimatske promene usled kojih sebi otežavamo život, i možda ga činimo nemogućim u budućnosti. A Zemlja, sve i ako ljudi izumru, nastaviće po starom, možda sa još bujnijim i raznolikijim živim svetom nego dok smo mi bili prisutni.

Upotreba argumenta neprirodnosti kao disharmoničnosti je veoma problematična $u$ kontekstu klimatskih promena. Ne samo što je to nevaljan argument iz svih razloga koje smo ranije naveli, on je i strateški loš izbor za ubeđivanje ljudi, jer depersonalizuje i apstrahuje problem klimatskih promena, koji nas se tiče, vrlo lično i neposredno. Klimatske promene nisu kazna neke kapriciozne majke prirode pred kojom treba da tražimo oproštaj grehova, one su neizbežna posledica prirodnih zakona koji ne pitaju o našoj moralnosti, intencijama, krivici ili pokajanju. Takve posledice nemaju funkciju disciplinovanja ili rehabilitovanja našeg 
ponašanja, one su konačni rezultat i ne treba ih posmatrati kao maglovitu pretnju, već kao stvarnost. Spram toga vredi koristiti argumente koji tu stvarnost čine transparentnom, a argument neprirodnosti je upravo suprotan.

\section{PRIRODA I NJENE SVRHE}

Poredak, međutim, ne mora da se postulira kao status quo, on može biti idealizovan, projektovan. Uostalom, priroda je toliko promenljiva da je fiksiranje nekog faktičkog stanja u najmanju ruku nemoguće, tako da se prirodni poredak ne očituje u stvarima kakve one jesu, već u procesima kroz koje te stvari prolaze, a kristalizuje se u svrhama ka kojima svaka prirodna stvar teži. Ove svrhe se ne smeju razumeti kao da su intencionalne (iako postoje doktrine koje ih tumače kao indikatore postojanja inteligencije iza kulisa ovog sveta, one nisu predmet naše rasprave ovde), već pre bezlično, kao predmete zajedničkog stremljenja koji se smisleno artikulišu tek racionalnom refleksijom. Tako sva živa bića teže ka tome da prežive što je duže moguće i da iza sebe ostave potomstvo. Ove dve svrhe pripadaju i onim živim oblicima kojima ne možemo pripisati nikakvu intencionalnost, pa čak ni posedovanje nagona - i biljke se „trude” da opstanu i da se umnože. Taj sistem svrha onda sačinjava prirodni poredak, i iako ga tek mi identifikujemo kao svrhovit sistem, on i dalje upravlja živim oblicima na ovoj Zemlji.

Neprirodno bi, onda, bilo svako ponašanje koje nije orijentisano ka ostvarenju tih svrha. Neprirodno je da životinja ne bude u potrazi za hranom kada je gladna. To nije nemoguće, u izvesnim okolnostima to se i dešava, ali onda kada se to dešava, to je uvek na štetu organizma o kojem je reč. Svrhe života su preživljavanje i razmnožavanje, jer jedino kroz njih se život održava. Aktivno izbegavanje ispunjavanja ovih svrha bi bilo ono što je neprirodno i što je kategorički loše. Homoseksualni parovi ne poseduju biološke mogućnosti da se reprodukuju, te tako ne mogu da ostvare jednu od dve postulirane ključne svrhe života. Homoseksualnost je, navodno, biološki ćorsokak i to je ono po čemu je homoseksualnost neprirodna. 
To beše treći tip argumenta neprirodnosti, najperfidniji tip koji razmatramo u ovoj raspravi. $\mathrm{U}$ ovom pojmu slepe svrhe zatičemo vrlo elaboratno konstruisano iskrivljenje mnogih bioloških doktrina. Mil je bio ubeđen da svrhovitost ne ulazi u uobičajena razumevanja prirodnosti, ali izgleda da je u tom pogledu bio odveć veliki optimista. Ovaj tip argumenta se, čak, ne koristi samo kao argument protiv homoseksualnosti, on je možda još poznatiji u drugim oblicima: kada se mladom bračnom paru sugeriše da ih prava sreća očekuje tek kada dobiju dete, ili, još notornije, kada se ženama spočitava da nikada neće biti istinske žene sve dok ne postanu majke. U svim ovim slučajevima, izostanak potomstva je nešto podrazumevano loše zato što je neprirodno, a neprirodno je zato što se time ne ostvaruje jedna od esencijalnih svrha života, razmnožavanje. ${ }^{24}$

Međutim, pretpostavka da su preživljavanje i razmnožavanje fundamentalne svrhe svakog živog bića nema svoje valjano utemeljenje u savremenoj nauci. Koliko god izgledalo da su ovo kategorije u kojima operiše evolucionističko razumevanje živog sveta, reč je zapravo o vrlo ozbljnoj zameni teza. U kontekstu ideja kao što su prirodno odabiranje, borba za opstanak i preživljavanje najsposobnijih, ljudski um je sklon da kontinuirane procese tumači kao svrhom vođene procese. Svi organizmi imaju nagon za preživljavanjem i nagon za razmnožavanjem, a preživljavanje i razmnožavanje su uvek otvoreni projekti koji se nikad ne mogu faktički dovršiti (organizam koji je preživeo jedan dan ispred sebe opet ima novi dan koji ima da preživi, organizam koji je iza sebe ostavio jednog potomka uvek može da poveća tu brojku), stoga se kao smisleni zaključak postavlja da su preživljavanje i razmnožavanje univerzalne svrhe ka kojima svi organizmi streme.

Ono što se u tom rezonovanju zanemaruje jeste da je po sredi vrsta selekcione pristrasnosti u kojoj o nekoj karakteristici sudimo samo na osnovu najvidljivijih egzemplara. Slično kao što u predstavi o idiličnoj

\footnotetext{
${ }^{24}$ Vredi podsetiti da se argument neprirodnosti u ovom pogledu često može licemerno upotrebljavati protiv različitih modaliteta razmnožavanja i roditeljstva, počev od samohranih roditelja, preko carskog reza, veštačke oplodnje i dalje. Za posebne slučajeve, videti Dušan Maljković, „Čudovišnost transmaterinstva” u: Postajanje majkom (ur. Ana Vilenica), u)zbu))na))), Beograd, 2013, str. 200-216.
} 
harmoničnosti prirode zanemarujemo krvavu borbu za opstanak, pri ovoj selekcionoj pristrasnosti nam za svaki jedan primer preživljavanja i razmnožavanja iz vidika izmiču brojni slučajevi u kojima se to ne dešava, a i onda kada ih uzimamo u obzir, ne razmatramo ih kao ravnopravne činjenice, već kao negativne činjenice koje idu u prilog pretpostavci jedinke bez potomaka ne posmatramo kao pozitivnu činjenicu živih bića koja se nisu razmnožila, već kao živa bića za koja važi negativna činjenica da nisu uspela da se razmnože. Takva perspektiva ne dokazuje da je razmnožavanje svrha života, već je pretpostavlja.

Pri takvom viđenju potpuno se promašuje doslednija interpretacija po kojoj nagoni za preživljavanjem i razmnožavanjem nisu naznake neke skrivene svrhe, već posledice načina na koji se odvija fenomen živog. Takva interpretacija zapravo je u temelju darvinističke ideje evolucije, i večna zasluga Čarlsa Darvina [Charles Darwin] je upravo u tome što je ponudio teoriju koja na mesto svih naših sklonosti ka svrhovitom tumačenju žive prirode stavlja vrlo jasno kauzalno tumačenje pojava. Zbog toga su brojni pokušaji da se evolucionistička doktrina koristi za opravdavanje nekakvih svrha i smislova života tragično i ironično zabludeli.

Deo krivice za ovo snosi i sam Darvin pošto je prilikom opisivanja svoje teorije posezao za terminima koji prosto vape za svrhovitom interpretacijom (npr. prirodno odabiranje), čega je i sam Darvin u izvesnoj meri bio svestan. ${ }^{25}$ Evoluciona teorija zapravo pokazuje kako su forme i obrasci koje živi svet sada poseduje kauzalne posledice nekolicine fundamentalnih procesa. Prvo, potomci nasleđuju karakteristike roditelja; drugo, potomci nisu identični svojim roditeljima, već im samo nalikuju i po nekim karakteristikama se razlikuju. Ove činjenice su istinite za sva živa bića, nezavisno od toga koliko dugo žive i da li su iza sebe ostavili potomke.

Treća univerzalna činjenica je postojanje borbe za opstanak, to jest, faktičkost situacije u kojoj su uslovi i resursi potrebni za život ograničeni. Četvrta činjenica je činjenica preživljavanja najprilagođenijih, koja je u izvesnoj meri truizam koji diktira da će u borbi za opstanak

${ }^{25}$ Čarls Darvin, Postanak vrsta, Akademska knjiga, Novi Sad, 2009, str. 100. 
dobro proći one jedinke koje poseduju karakteristike koje su prilagođene situaciji u kojoj se nalaze, šta god to u konkretnom slučaju bilo. Ove četiri činjenice, uzete zajedno, kao kauzalnu posledicu daju proces prirodnog odabiranja: u borbi za opstanak održavaju se jedinke koje poseduju neke prilagođene karakteristike, koje se onda mogu preneti sa manjim izmenama na narednu generaciju. Primetimo da nigde u ovom procesu preživljavanje niti razmnožavanje nisu zagarantovani niti stoje kao očekivane svrhe.

Preživljavanje je posledica posedovanja povoljnih karakteristika, razmnožavanje je uslovljeno preživljavanjem, a posledica je nasleđivanja karakteristika. Naime, kada jedan organizam nastane od drugog i tom prilikom nasleđuje osobine roditelja, jedna od osobina koje se mogu očekivati da će se naslediti je osobina proizvođenja drugog sebi sličnog organizma. A za očekivati je da će brojnije biti one jedinke koje nasleđuju osobinu uvećavanja svoje brojnosti. Jednako kao što nijedna karakteristika živog sveta nije poželjna po sebi, ni snaga ni brzina ni inteligencija nisu podrazumevano poželjne, već je njihova poželjnost posledica okolnosti u kojima se živi organizam zatiče, tako i opštost preživljavanja i razmnožavanja nije svrha po sebi, već posledica okolnosti u kojima se živi organizmi zatiču.

Vrlo dobro opovrgavanje svrhovitih mehanizama u evoluciji Darvin navodi prilikom kritikovanja ideje da organizmi poseduju karakteristike koje su korisne drugim organizmima, a ne njima samima, na primer, da su neka „organska bića stvorena lepa zbog čovekovog zadovoljstva.”26 O tome Darvin kaže: „Prirodno odabiranje ne može proizvesti nijednu modifikaciju kod jedne vrste i isključivo radi koristi neke druge vrste, mada u celoj prirodi jedna vrsta neprekidno zadobija prednost i koristi se građom drugih vrsta. Ali prirodno odabiranje može, $i$ to čini često, da proizvede građe neposredno štetne za druge životinje, kao što su otrovni zubi kod šarke ili legalica kod ose potajnice, kojom ona polaže svoja jaja u živo telo drugih insekata." 27 U ovoj tvrdnji jasno prepoznajemo da korist uvek ostaje na mestu na kom se javlja osobina ili

\footnotetext{
${ }^{26}$ Isto, str. 215.

${ }^{27}$ Isto, str. 216.
} 
promena. Takva je kauzalna korist, što se vidi na slučajevima osobina koje su štetne za druga bića, čime indirektno koriste matičnom organizmu. Svrhovita korist ne samo da nije ograničena na takav način, već se po definiciji nalazi izvan organizma kao nešto čemu se teži. Da je svrhovita korist moguća među živim oblicima, onda bi one strukture koje ljudi kod životinja nazivaju lepim nastale tek onda kada bi se pojavili ljudi, što očevidno nije slučaj.

Ovim se direktno pobija smislenost trećeg tipa argumenta neprirodnosti, jer se opovrgava pretpostavka da su razmnožavanje i preživljavanje svrhe života, već se te kategorije razumevaju kao posledice života. U konkretnom obliku tog argumenta kao argumenta protiv homoseksualnosti, gde su homoseksualni odnosi neprirodni jer ne mogu da proizvedu potomstvo, opovrgavanje je jasno: ne samo što nepreživljavanje i nerazmnožavanje nisu neprirodni, to su sasvim prirodne karakteristike živih bića; uostalom, živa bića koja nisu ostavila potomke nisu time bila išta manje živa. Zamena teza koju smo ovom prilikom demaskirali je ono što smo na početku ove analize nazvali perfidnim elementom ovog argumenta.

Neko bi na ovo, međutim, mogao da potegne pitanje kako se karakteristika homoseksualnosti uopšte javlja i propagira kroz generacije ako homoseksualni odnosi ne proizvode potomstvo. Pored banalne neupućenosti ovakvog pitanja - jer homoseksualnost nije isto što i nemogućnost imanja potomaka - $\mathrm{u}$ njemu se ponovo javlja ista zamena teza kao i u prethodnom argumentu. Činjenično stanje stvari, koje uključuje postojanje homoseksualnosti, ne zahteva nekakvo svrhovito opravdanje, činjenično stanje stvari samo ukazuje na to da ne znamo sve kauzalne procese koji su do njega doveli. Homoseksualnost postoji, deo je sveta i prirode; samim tim, homoseksualnost je savršeno prirodna, ma kakve (neupućene) stavove neki o tome imali. Naravno, homoseksualnost je ovde uzeta samo kao prigodan primer, i ovo obaranje argumenta neprirodnost može uz minimalne izmene da se upotrebi u svim drugim instancama, kako onim koje smo pomenuli, tako i nebrojenim koje nismo. 


\section{ZAKLJUČAK}

Rezimirajmo analizu sprovedenu na prethodnim stranicama. Prepoznali smo tri istaknuta tipa argumenata koji kao kriterijum za procenjivanje (ne)prihvatljivosti delanja uzima koncept neprirodnosti. Iako se svakom od tih argumenata u pojedinačnim upotrebama može prigovoriti štošta u pogledu njihove materijalne ispravnosti, uvideli smo da se njihova problematičnost sastoji i $u$ ispraznoj upotrebi pojma neprirodno, iza kojeg su se uvek pronalazile neumesne pretpostavke koje su se pokušale prokrijumčariti zaodenute $\mathrm{u}$ ove kvazinaturalističke argumente.

Prvi tip argumenta neprirodnosti, koji neprirodnost izjednačava sa veštačkim i nespontanim, nevaljan je zato što je karakteristika artificijelnosti i sama nebulozna. Upotreba ovakvog argumenta se ne oslanja na precizne i diskriminativne kriterijume, već pre kapitalizuje na ljudskom strahu od novog i nepoznatog. Drugi tip argumenta neprirodnosti, koji neprirodnost izjednačava sa disharmonijom, neuspešan je zato što ne može dosledno da opravda vezu između prirode i harmonije. Pretpostavka koja se krije u tom argumentu jeste pretpostavka da je status quo po definiciji dobar i nešto što se treba održati, usled čega se mnogi od ovih „harmoničnih” argumenata konačno pokazuju kao suštinski reakcionarni. Najzad, treći tip argumenta neprirodnosti nju izjednačava sa navodno objektivno utvrđenom prirodnom svrhom. Međutim, ono što takav argument pokušava da podmetne jeste privid objektivnosti za neke tendenciozno odabrane svrhe, u nadi da će partikularni interesi biti prihvaćeni kao prirodna nužnost. U svim ovim slučajevima, termin neprirodno nije upotrebljavan kao samostalan i suvisao pojam, već uvek kao maska koja prikriva neku parcijalnu doktrinu. Drugim rečima, svi ovi argumenti su velike zamene teza, jer jedino što oni iskazuju jeste da su izvesna stanovišta sklona da stvari sa kojima su saglasne imenuju kao prirodne, a one sa kojima su u sukobu etiketiraju kao neprirodne.

Ovom prilikom najviše smo govorili o konkretizaciji tih argumenata na primeru homoseksualnih odnosa, ali imali smo prilike da vidimo i druge oblasti u kojima se oni mogu pojaviti. U svim tim 
slučajevima, ovaj argument se pokazivao kao nedovoljan, pa čak i onda kada je korišćen ne kao glavni, već kao pomoćni, ilustrativni argument. U tome lako prepoznajemo dvostruku korist od izvođenja ove analize argumenta. S jedne strane, poučava nas da prepoznamo slučajeve kada nam se $u$ ruhu jednih izraza pokuša podmetnuti neprihvatljiva pretpostavka, a sa druge strane nas upozorava da ne oslabljujemo sopstvene argumentativne pozicije time što ćemo da posegnemo za beskrupuloznim taktikama koje smo možda videli kod protivnika. Rečju, koncept neprirodnog sasvim je beskoristan za ustanovljavanje vrednosnih sudova.

$\mathrm{Na}$ prvi pogled, ovo može izgledati kao odveć radikalan zaključak. Uostalom, ideja prirode ima neko pozitivno značenje, zar nije smisleno očekivati da će se i za ideju neprirodnog konačno naći neki konsenzus? Ka tome odgovaramo - možda nas je ta ideja neprirodnog od samog početka odvela na pogrešan trag. Nesuvislost tog pojma je pokazala da je fiksiranje njegovog značenja kao kakav lov u mutnom. Ako već tražimo pojam koji bi bio komplementaran pojmu prirodno, onda je za to mnogo dosledniji pojam natprirodnog. Naravno, njegova upotreba je opravdana samo u domenu fantastike i ljudske mašte, gde bi taj pojam i njemu slični trebalo da budu - uglavnom bezopasni.

\section{LITERATURA}

Čarls Darvin, Postanak vrsta, Akademska knjiga, Novi Sad, 2009.

Dušan Maljković, „Čudovišnost transmaterinstva” u: Postajanje majkom (ur. Ana Vilenica), u)zbu))na))), Beograd, 2013, str. 200-216.

Džon Stjuart Mil, Prirodno i neprirodno, Karpos, Loznica, 2008.

Frank L. Lambert, „A Modern View of Entropy” u: Chemistry, Vol. 15, Iss. 1. (2006), str. 13-21.

Immanuel Kant, „Geschichte und Naturbeschreibung der merkwürdigsten Vorfälle des Erdbebens" u: Immanuel Kant's kleinere Schriften zur Naturphilosophie. Zweite Abtheilung (Hg. J. H. Kirchmann), L. Heimann's Verlag, Berlin, 1783, str. 333-372.

Isaiah Berlin, Political Ideas in the Romantic Age, Princeton University Press, Princeton, 2006.

Monteskje, O duhu zakona, Gradac, Čačak, 2001. 
Nihal Petek Boyaci Gülenç, „An Enquiry on Physis-Nomos Debate: Sophists” u: Synthesis Philosophica 61 (1/2016), str. 39-53.

Paul L. Vasey, „Homosexual Behaviour in Primates: A Review of Evidence and Theory" u: International Journal of Primatology, Vol. 16, Iss. 2. (1995), str. 173-204.

\author{
GORAN RUJEVIĆ \\ University of Novi Sad, Faculty of Philosophy
}

VACUOUSLY UNNATURAL

\begin{abstract}
The argument of unnaturalness is used to justify the attribution of a (usually) negative value to things or actions by deeming them unnatural. This argument is found applied to various topics, from the purportedly unnatural genetically modified organisms to the purportedly unnatural homosexual relations. Whenever something is dubedd as unnatural, it is thought of as either something artificial, or something disharmonious, or something that goes against the natural purposes. By analyzing all these instances, we arrive at the conclusion that the term unnatural is never used in a sensical and reasonable manner. Artificial cannot be unnatural, as even artificial things must obey natural laws. Disharmonious is also a poor opposite of natural, as the very postulate of nature being harmonious is an unwarranted supposition. Violation of natural purposes is a particularly egregious interpetation of unnaturalness, as it masks ulterior motives and interests in the guise of objective propositions. The only sensical opposite of the notion of the natural is that of the supernatural, which in itself has no place in evaluating real things and events.
\end{abstract}

Keywords: artificial, harmony, homosexuality, natural, purpose, unnatural

Primljeno: 27.8.2019.

Prihvaćeno: 2.11.2019. 